\title{
Anatomical and Histological Studies on the Hyoid Apparatus and its Associated Musculature in the Domestic cat (Felis domestica)
}

\author{
Farag, F.M.* and EL-Saba A. A. ** \\ Anatomy. Dept. Fac. Vet. Med. Cairo University.* \\ Histology. Dept. Fac. Vet. Med. Cairo University. **
}

Received October, accepted for publication December 2012

\section{Abstract}

This work was carried out on the heads of sixteen apparently healthy adult domestic cats of various sexes. The available literatures dealing with the gross anatomy of the hyoid apparatus of various species of domestic animals were reviewed. The Manual dissection, dry bony specimens as well as histological examination were used according to the purpose under investigation. The study described the six segments forming the cat hyoid apparatus; Tympanohyoideum, Stylohyoideum, Epihyoideum, Ceratohyoideum, Basihyoideum and Thyrohyoideum. Elevenpairs of muscles where attached to the hyoid apparatus. The most enlarged of these muscles were those that retract the hyoid bone caudally, the sternohyoid muscle and rostrally, the geniohyoid muscle as well as those controlling the tongue movement, styloglossus and hyoglossus. The histological studies showed that the Tympanohyoideum and Ceratohyoideum were mostly hyaline cartilage, the Epihyoideum was partly hyaline and partly fibrous, the Stylohyoideum and Thyrohyoideum were partly hyaline and partly osseous while the Basihyoideum was completely ossified.

The results obtained were photographed, described and discussed with those of other domestic animals.

Keywords: Anatomy-Histology hyoid apparatus- domestic cat.

\section{Introduction}

In veterinary anatomy, the term hyoid apparatus was the collective term used to refer to the bones of the tongue; a pair of Stylohyoidea, a pair of unpaired Basihyoideum that provide the skeletal supporting for the tongue 
and larynx, and the site of insertion of the muscles of the biodynamic system which regulates mastication, deglutition and phonation (Shoshani and Marchant ,2001). The anatomy of the hyoid apparatus of the domestic animals shows great similarity in broad overview, concerning the number of its segments, and the muscles connecting with them. However the hyoid apparatus vary in the relative size of its segments, its articulation as well as the extent to which its constituent parts are ossified, cartilaginous or ligamentous. The first hint on the peculiarities of the hyoid apparatus of the cat was published by Owen (1835) and Pocock (1916) who studied the hyoid apparatus in five cat species. In the clinical field, Lantz, and Salisbury (1989) recorded tumors in the hyoid bone in seven species of dogs and provided their surgical approach. Zantingh et al (2013) studied the role of some hyoid muscles in the position of the hyoid apparatus and larynx in the horse. The present study is therefore an attempt to describe accurately the structure and relative topographical position of the hyoid apparatus and its associated muscles of the cat which still remains of fundamental practical and clinical importance.

\section{Material and Methods} of different ages and sexes (8 male -8 female) were used in the present investigation. Both common carotid arteries were thoroughly flushed with warm $\left(40 c^{\circ}\right)$ saline solution and the specimens were then injected with formalin solution (10\% formalin, $4 \%$ phenol, $1 \%$ glycerin), followed by immersion in formalin solution for 3-4 days (Tomsett and Wakelly, 1965). Six specimens were used for manual dissection to investigate the hyoid bone in situ as well as to study the origin and insertion of the associated hyoid, tongue, pharyngeal and laryngeal muscles. Six other heads were used to prepare dry bony specimens for the skull and hyoid bone. The remaining four specimens were used for the histological examination of the hyoid apparatus.

Six heads were used for the preparation of dry specimens of skull and hyoid apparatus. After careful removal of all muscular and ligamentous attachments, as possible the bones were washed under running water then soaked for 2-3 days in deodorizing solution of $0.03 \%$ ammonia then another 2-3 days in 95 $100 \%$ acetone for degreasing. This process was repeated 2-3 times until the greasy texture disappeared, then washed in a slow stream of running water to remove ammonia 
or acetone residues. For bleaching, bones were soaked in hydrogen peroxide $\left(\mathrm{H}_{2} \mathrm{O}_{2}\right)$ with a concentration of $1 \%-2 \%$ for five to seven days. The specimens were then removed and soaked in fresh water for two days to eliminate odor and remove any chemical residue then the skulls left to dry for 2-3 days at room temperature while the hyoid bones preserved in $10 \%$ formalin solution to prevent their dryness and shrinkage (Sullivan et al.1999). The Vernier caliper used to measure the length and thickness of each segment of the hyoid bone.

The specimens were photographed using Olympus digital camera SP600UZ 12 mega pixel.

The nomenclature used was adopted according to the Nomina Anatomica Veterinaria (2005).

For the histological examination, four hyoid bones were freshly removed from the heads and cleaned from the attached soft tissues then washed with $0.9 \%$ saline solution and then immediately immersed in different fixatives $(10 \%$ neutral buffered formalin, Bouin $s$ fluid and Zenker s formol). The samples were processed (dehydrated and cleared by alcohol and xylene respectively), and then embedded in paraffin wax. Tissue sections of 5-6 $\mu \mathrm{m}$ thickness were prepared and stained with Harris haematoxylin and eosin (H\&E) and Crossmon s trichrome stain. The fixatives and staining method were used as outlined by Crossman (1937) and Drury and Wallington (1980).

\section{Results}

The cat hyoid apparatus can be divided into suspensory and basal portions. The suspensory portion connected to the base of the skull and consisted of the paired Tympanohyoideum, Stylohyoideum, Epihyoideum and Ceratohyoideum while the basal portion comprised the Basihyoideum and the paired Thyrohyoideum.

Tympanohyoideum (Figs.1, 2, 3, $7,8 / 1$ ), represented the upper most segment of the hyoid apparatus that articulated with the mastoid process of the petrous temporal bone (Fig.1/A), through fibrous tissue (Fig.2/7), caudoventral to the external acoustic meatus (Fig.1/B) and extended cranioventrally to articulate with the Stylohyoideum through hyaline cartilage synchondrosis (Fig.2, 3/8, Fig. 11). It measured about $10.0-12.0 \mathrm{~mm}$ in length and was relatively broad at its proximal end (about $2.0 \mathrm{~mm}$ ) and narrowed distally to (about $1.0 \mathrm{~mm}$ ) in breadth (table 1). Microscopical examination revealed that the Tym- 
panohyoideum was formed of hyaline cartilage (Figs. 9, 10).

Stylohyoideum (Figs., 1, 2, 3, 7, $\mathbf{8} / \mathbf{2}$ ), extended cranioventrally, between the Tympanohyoideum and Epihyoideum, where it was connected with these two segments via hyaline cartilage synchondrosis (Fig. 2, 3 /8, 9, Fig 11/ C). It measured about $10.0-12.0 \mathrm{~mm}$ in length and $1.0-1.2 \mathrm{~mm}$ in thickness (table 1). Microscopical examination of the Stylohyoideum showed spongy bone in the central portion and hyaline cartilage at both ends (Fig. 11, 12)

Epihyoideum (Figs., 1, 2, 3, 7, 8/3) extended cranioventrally between the Stylohyoideum and Ceratohyoideum where it articulated with these two segments via hyaline cartilage synchondrosis (Fig.2, 3/9, 10, Fig.13). It measured about 7.0-9.0 $\mathrm{mm}$ in length and $1.2-1.4 \mathrm{~mm}$ in breadth (table 1). Microscopical examination of the Epihyoideum showed hyaline cartilaginous part rostrally (Fig.13/ C) and fibrous part caudally (Fig.13/ L).

Ceratohyoideum (Figs., 1, 2, 3/4) extended caudoventrally between the Epihyoideum and Basihyoideum. It articulated with the former segment via hyaline cartilage synchondrosis (Fig.2, 3/ 10) and fused caudally with the corresponding edge of the latter segment. It measured about $6.0-6.8 \mathrm{~mm}$ in length and 1.3-1.5 $\mathrm{mm}$ in breadth (table 1).

Basihyoideum (Figs.1, 2, 3/5) was in the form of a short transverse bony segment that situated ventral to the base of the cranium on a level with the middle of the basisphenoid. Its cranial border was slightly convex and lacking the lingual process while the caudal border was consequently concave and separated from the rostral border of the body of the thyroid cartilage by an interval of about $6.0-8.0 \mathrm{~mm}$. It measured about $\mathbf{9} . \mathbf{0}-12.0 \mathrm{~mm}$ in length and about 1.5-.1.7 mm in breadth (table 1). Microscopically it was formed of spongy bone with marrow cavity in its center (Fig. 14).

Thyrohyoideum (Figs.1, 2, 3/6) extended in a caudodorsal direction with slight lateral inclination. Its rostral end fused with the Basihyoideum while the caudal end was attached to the rostral cornu of the thyroid cartilage via short ligament. It measured about $8.0-10.0 \mathrm{~mm}$ in length and 1.4-1.8 $\mathrm{mm}$ in breadth (table 1). Histologically, it was formed of spongy bone near its junction with the Basihyoideum and hyaline cartilage near its connection to the thyroid cartilage (Fig. 15). 
Muscles associated with the hyoid apparatus:

M. sternohyoideus (Figs. 4, 5, 6, $7,8 / 11$ ), thick muscle that attached caudally to the lateral surface of the Maniburum sterni as the medial portion of the $M$. sternothyrohyoideus (Figs. 6, 7 /22), and ascended along the ventral aspect of the neck in contact with its contralateral muscle to terminate on the caudal and ventral aspects of the Basihyoideum. From point of its size the sternohyoid muscle represented the strongest of the hyoid muscles.

M. geniohyoideus (Figs. 5, 7, 8 112) long thick muscle that attached rostrally to the caudal aspect of the body of the mandible and terminated caudally on the rostral face of the Basihyoideum. From point of its size the geniohyoid muscle represented the second of the strongest hyoid muscles.

M. mylohyoideus (Figs.5, 6/13), thin flat muscle that attached to the medial surface of the ramus of the mandible and its fibers extended caudoventrally where it united with its contralateral muscle at a median raphe then extended caudally to terminate in the rostral aspect of the Basihyoideum.

M. thyrohyoideus (Figs. 7, 8 /14) was flat muscle attached to the latJ. Vet. Anat. eral surface of the ventral half of Thyrohyoideum and extended caudally to terminate on the lateral surface of the thyroid lamina.

M. occipitohyoideus (Fig.6/15) was small muscle attached to the caudal aspect of the dorsal half of the Tympanohyoideum. It arose from the occipital bone just caudal to the jugular process. It is the only muscle connecting the hyoid bone with the skull.

M. hyopharyngeus (Figs. 6, 7 /16) was one of the pharyngeal muscles that attached to the ventrolateral surface of the Thyrohyoideum as well as the lateral part of the Basihyoideum. It then extended dorsally on the pharyngeal wall and terminated at the pharyngeal raphe.

\section{M. stylopharyngeus caudalis} (Figs. 6/17) was one of the pharyngeal muscles in the form of narrow strip that attached to the medial aspect of the Tympanohyoideum and adjacent portion of Stylohyoideum and descended to terminate into the dorsal wall of the pharynx

M. styloglossus (Figs. 6, 7, 8 /18), was one of the tongue muscles in the form of broad muscle strip that originated from the lateral aspect of the Tympanohyoideum and adjacent portion of Stylohyoideum. It extended cranioventrally along the

Vol 6 No 2, (2013) 51 - 66 
lateral surface of the tongue then swerved to its ventral surface where it terminated at the apex linguae.

M. hyoglossus (Figs.7, 8 /19), one of the tongue muscles in the form of narrow strip that attached to the ventrolateral surface and rostral edge of the Thyrohyoideum and extended craniodorsally to terminate on the lateral surface of the body of the tongue.

M. ceratohyoideus (Fig. 8 /23) was in the form of small triangular muscle that extended in cranioventral direction in the angle between the rostral border of Thyrohyoideum and caudal border of Ceratohyoideum. It was located medial to the $\mathrm{M}$. hyopharyngeus.

M. hyoepiglotticus (Fig. 9 /24) was represented by small muscle that extended from the ventral portion of the lingual surface of the epiglottis cartilage to the caudal aspect of the Basihyoideum.

\section{Discussion}

In Accordance with Reidenberg and Laitman (1994) in the toothed whales, König and Liebich (2004) in the domestic mammals, and Shoghy and Saber (2013) in the camel, the cat hyoid apparatus could be divisible into two portions; a basal portion that comprised the Basihyoideum and the paired Thyrohyoideum and a suspensory portion that consisted of the paired Ceratohyoideum, Epihyoideum, Stylohyoideum and Tympanohyoideum connecting the basal portion to the skull base.

In agreement with Gasc (1967) and Walker and Homberger (1992), the hyoid complex comprised 11 elements as, single Basihyoideum and paired Tympanohyoideum, Stylohyoideum, Epihyoideum, Ceratohyoideum and Thyrohyoideum. Shoshani and Marchant (2001) recorded that in veterinary anatomy, the term hyoid apparatus was the collective term used to refer to the bones of the tongue; a pair of stylohyoidea, a pair of thyrohyoidea, and unpaired Basihyoi-deum. The authors mentioned that the mammalian hyoid apparatus in general consisted of nine bones (single basihyal, and paired thyrohyals, epihyals, ceratohyals and stylohyals). These articulate in a box-like fashion and attach via tympanohyal cartilages to the base of the cranium.

With regards to the articulation of the hyoid bone to the base of the cranium, the present study revealed that in the domestic cat the Tympa- 
nohyoideum articulated with the mastoid process of the petrous temporal bone, caudoventral to the external acoustic meatus via fibrous tissue. Takada et al. (2009) mentioned that the tympanohyal of the mustelids and procyonid was possibly covered and hidden by the tympanic bulla. Concerning the latter articulation, the Tympanohyoideum articulated with the styloid process of temporal bone, this was mentioned by Hillmann (1975) in the pig, Saber and Hofmann (1985) in six ruminant species and König and Liebich (2004) in the horse, with the jugular process of the occipital bone as reported by Barone et al.(1973) and Little and Lane (1986) in the rabbit or with the nuchal process of the squamous temporal bone as revealed by König and Liebich (2004) in the pig. On the other hand, Farag et al. (2012) revealed that the hyoid bone in the rabbit lacked the Stylohyoideum and Tympanohyoideum and thus didn't articulate with the bones of the cranium and its main connection to these bones was through the jugulohyoid muscle and considered this connection as a sort of synsarcosis.

The present study revealed a positional level of the Basihyoideum with the middle of basisphenoid. Weissengruber et al. (2002) mentioned that in the cheetah and domestic cats, it showed a position ventral to the cranial base or the atlas, While in the lion, tiger and adult jaguar it was displayed a relatively caudal position in the middle or caudal part of the neck on a level with the body of the 3rd to 5th cervical vertebra.

The Basihyoideum of the cat lacked the lingual process as also mentioned in carnivora by König and Liebich (2004) and Shoghy and Saber (2013) in the camel. Farag et al. (2012) recorded small lingual process in the rabbit. On the other hand, König and Liebich (2004) mentioned the lingual process in the horse was long while that of ruminants was short and tuberous.

Concerning the relative lengths of the suspensory elements of the hyoid apparatus, the present study stated that the Tympanohyoideum, Stylohyoideum and Epihyoideum bearded approximately equal lengths and were slightly longer than the Ceratohyoideum. In camel, the epihyoids were twice the length of ceratohyoids (Shoghy and Saber, 2013), in the horse were small wedge-shaped pieces interposed between the ceratohyoids and stylohyoids or fused with the stylohyoids while those cattle were almost as large as the ceratohyoids. The epihyoids in carnivora were cylindrical and in pig were replaced by the 
epihyoid ligament (König and Liebich, 2004). Shoshani and Marchant (2001) mentioned that the hyoid apparatus of elephant lack both Epihyoideum and Ceratohyoideum, creating a gap between the stylohyals and basihyal-thyrohyal complex that often fused forming $U$-shaped unit and descended downwards away from the cranium similar to the situation found in humans (Grey, 1901).

Concerning the hyoid musculature, the present study recorded the enlargement of the muscles that retract the hyoid bone caudally, the sternohyoid muscle and the muscle that protract the bone rostrally, the geniohyoid muscle as well as those controlling the tongue movement, styloglossus and hyoglossus. Similar observations were mentioned by Reidenberg and Laitman (1994) in the toothed whales who added that these muscles may be particularly important in a specialized prey capture behavior called suction feeding.

The histological studies performed on the hyoid apparatus of the adult cat revealed that the Tympanohyoideum and Ceratohyoideum were mostly hyaline cartilage, the Epihyoideum was partly hyaline and partly fibrous, the Stylohyoideum and Thyrohyoideum were partly hyaline and partly osseous while the Basihyoide- um was completely ossified. On the other hand, Weissengruber et al. (2002) mentioned that the Epihyoideum, in the cheetah and the domestic cat was also ossified while, in lion, tiger and jaguar represented by a ligamentous structure consisting of elastic and collagenous fibers and was therefore named Lig. Epihyoideum situated within the lateral pharyngeal wall, and added that in the lion, a small bony structure was embedded within this ligament. Shoghy and Saber (2013) in the camel mentioned that all parts of the hyoid bone were ossified at age 7.5-8 years except the Basihyoideum which remained cartilaginous. It might be added that the Stylohyoideum was articulated with both Tympanohyoideum and Epihyoideum through cartilaginous articulation. Similar findings were also recorded byTakada et al. (2009) in carnivora that designated the cartilaginous articulation between the tympanohyal and stylohyal as the tympano-styloid synchondrosis.

\section{References}

Barone, R., Pavaux, C., Blin, P.C. and Cuq, P. (1973): Atlas of Rabbit Anatomy (Masson et Cie, Paris), $11-50$ 
Crossman, G. (1937): A modification of mallory $s$ connective tissue stain with a discussion of principles involved, 69: 33-38

Drury, R.A.B. and Wallington, E.A. (1980): Carliton s histological technique. Fourth Edition Oxford University Press, New York, Toronto.

Farag, F.M., Daghash, S.M. Mohamed, E.F., Hussein, M.M. and Hagrass, S.M. (2012): Anatomical Studies on the Skull of the Domestic Rabbit (Oryctolagus cunicuIus)With Special Reference to the Hyoid Apparatus. J. Vet. Anat. Vol. 5, No. (2), 49-70.

Gasc, J.P. (1967): Sequelette hypobranchial. In P.P. Grasse (ed.), Traite de Zoologie 16(1): 55o-583, 1103-1106. Paris: asson et Cie Editeurs.

Grey, H. (1901): Gray's Anatomy, descriptive and surgical. (1974 printing edited by T.P. Pick and R. Howden) Philadelphia: Running Press.

Hillmann, D.J. (1975): (Procaine osteology: skull). In "Sisson and Grossman "anatomy of domestic animals. $5^{\text {th }}$ edition Vol. 1 and 2 reviewed by R. Getty. W.B. SAUN-
DERS COMPANY Philadelphia, London.

König, H.E. and Liebich, H.G. (2004): Veterinary Anatomy of Domestic Mammals. Textbook and Colour Atlas. $4^{\text {th }}$ ed. Schattauer GmbH, Holderlinstrabe3 D-70174 Stuttgart, Germany.

Lantz, G.C. and Salisbury, K.S. (1989): Surgical excision of ectopic thyroid carcinoma involving the base of the tongue in dogs: J. Am. Vet. Ed. Assoc., 195: 1606-1608

Nomina Anatomica Veterinaria (2005): $5^{\text {th }}$ Ed. Prepared by the international committee on Veterinary Gross Anatomical Nomenclature .General Assembly of the word Association of veterinary anatomists, Knoxville, TN (U.S.A.) 2003. Hannover, Columbia, Gent, Sapporo. (Electronic version).

Owen, R. (135): On the anatomy of the cheetah, Felisjubata, Schreb. Trans. Zool. Soc. London 1, 129136.

Pocock, R.I. (1916): On the hyoidean apparatus of the lion (F. Leo) and related species of Felidae. Ann. Magazine Natural History, Zoology, Bot. Geol. 8, 222-229.

Reidenberg, J.S. and Laitman, J.T. (1994): Anatomy of the hyoid apparatus in Odontoceti (toothed 
whales): specializations of their skeleton and musculature compared with those of terrestrial mammals. Anatomical record, 240(4):598-624.

Saber, A.S. and Hofmann, R.R. (1985): A comparative study of the hyoid bone (Os hyoides) of 6 ruminant species (Ruminantia Scopoli, 1777). Anat. Anz. 1985; 158(1):4350.

Shoghy, K.M. and Saber, A.S. (2013): Development of the hyoid bone (Os hyoiseum) in the onehumped camel (Camelus dromedarius). J. Vet. Anat. Vol.6 No.11-7.

Shoshani J. and Marchant G.H. (2001): Hyoid apparatus: a littleknown complex of bones and its "contribution" to proboscidean evolution, The World of Elephants - International Congress, Rome, pp. 668-675.

Sullivan, L.M, Romney, H., and October, C.P. (1999): Cleaning and Preserving Animal Skulls. The University of Arizona Cooperative Extension. http://ag.arizona.edu./pubs/ natresourxes/az1144. Pdf

Takada, Y., Izumi, M. and Gotoh, k. (2009): Comparative Anatomy of the Hyoid Apparatus of Carnivores. Mammal Study 34(4):213-218.

Tomsett, D.H. and Wakeley, C W. (1965): Anatomical Techniques. $1^{\text {st }}$ Edition. E\& Living Stone Ltd. Edinburgh and London.

Walker, W.F. and Homberger, D.G. (1992): Vertebrate dissection $\left(8^{\text {th }}\right.$ edn). Fort Worth (Texas): Harcourt Brace Jovanovich Collage Puplishers.

Weissengruber, G. E., Forstenpointner, G., Peters, G., KübberHeiss' A. and Fitch, W.T.(2002): Hyoid apparatus and pharynx in the lion (Pantheraleo), jaguar (Pantheraonca), tiger (Pantheratigris), cheetah (Acinonyxjubatus) and domestic cat (Felissilvestris f. catus). Journal of Anatomy Vol. 201, Issue 3 pages 195-209.

Zantingh, A.J., Ducharme, N.G. , Mitchell, L.M. And Cheetham, J. (2013): Effects of hypoglossal nerve block and electrical stimulation of the thyrohyoideus muscles on position of the larynx and hyoid apparatus in healthy horses. Am J Vet Res. 74(5): 784-9. Doi: 10.2460 / ajvr.74.5.784. 
Table (1): Summary of morphological findings and measurements (in $\mathrm{mm}$ )

\begin{tabular}{|l|l|l|l|}
\hline segment & Length(mm) & Breadth(mm) & type \\
\hline Tympanohyoideum & $10.0-12.0$ & $1.0-2.0$ & hyaline cartilage \\
\hline Stylohyoideum & $10.0-12.0$ & $1.0-1.2$ & $\begin{array}{l}\text { Spongy bone / } \\
\text { hyaline cartilage }\end{array}$ \\
\hline Epihyoideum & $7.0-9.0$ & $1.2-1.4$ & $\begin{array}{l}\text { hyaline cartilage/ } \\
\text { Fibrous }\end{array}$ \\
\hline Ceratohyoideum & $6.0-6.8$ & $1.3-1.5$ & hyaline cartilage \\
\hline Basihyoideum & $9.0-12.0$ & $1.5-.1 .7$ & Spongy bone bone / \\
\hline Thyrohyoideum & $8.0-10.0$ & $1.4-.1 .8$ & $\begin{array}{l}\text { Spongy bone cartilage } \\
\text { hyaline callage }\end{array}$ \\
\hline
\end{tabular}

Table (2): Summary of the area of attachment of the muscles associated with the hyoid bone of the cat.

\begin{tabular}{|l|l|}
\hline Muscle & Attachment to hyoid bone \\
\hline M. sternohyoideus & Caudal and ventral aspects of the Basihyoideum \\
\hline M. geniohyoideus & Rostral aspect of Basihyoideum. \\
\hline M.mylohyoideus & Rostroventral aspect of Basihyoideum \\
\hline M. ceratohyoideus & $\begin{array}{l}\text { The rostral border of Thyrohyoideum and caudal border of } \\
\text { Ceratohyoideum. }\end{array}$ \\
\hline M.thyrohyoideus & Ventral half of the Thyrohyoideum \\
\hline M.occipitohyoideus & Caudal aspect of the dorsal half of the Tympanohyoideum. \\
\hline M. hyopharyngeus & $\begin{array}{l}\text { Ventrolateral surface of the Thyrohyoideum and the lateral part } \\
\text { of the Basihyoideum. }\end{array}$ \\
\hline $\begin{array}{l}\text { M. stylopharyngeus- } \\
\text { caudalis }\end{array}$ & $\begin{array}{l}\text { Medial aspect of the Tympanohyoideum and adjacent portion } \\
\text { of Stylohyoideum. }\end{array}$ \\
\hline M. styloglossus & $\begin{array}{l}\text { Lateral aspect of the Tympanohyoideum and adjacent portion } \\
\text { of Stylohyoideum. }\end{array}$ \\
\hline M. hyoglossus & Ventrolateral surface and rostral edge of the Thyrohyoideum \\
\hline M. hyoepiglotticus & \begin{tabular}{l} 
The caudal aspect of the Basihyoideum. \\
\hline
\end{tabular} \\
\hline
\end{tabular}




\section{Legend for figures from 1-9}

1Tympanohyoideum, 2 Stylohyoideum, 3 Epihyoideum, 4 Epihyoideum, 5 Ceratohyoideum, 6 Basihyoideum, 7 Thyrohyoideum, 8 Fibrous tissue (Syndesmosis), 9 Hyaline cartilage (synchondrosis), 4 chondrosis), $12 \mathrm{M}$. sternohyoideus, $13 \mathrm{M}$. geniohyoideus, $14 \mathrm{M}$. mylohyoideus, $15 \mathrm{M}$. thyrohyoideus, $16 \mathrm{M}$. occipitohyoideus, $17 \mathrm{M}$. hyopharyngeus, $18 \mathrm{M}$. stylopharyngeus caudalis, $19 \mathrm{M}$. styloglossus, $20 \mathrm{M}$. hyoglossus, $21 \mathrm{M}$. genioglossus, $22 \mathrm{M}$. sternothyroideus, $23 \mathrm{M}$. sternothyrohyoideus, $24 \mathrm{M}$. ceratohyoideus, $25 \mathrm{M}$. hyoepiglotticus,

A Processus mastoideus, B Meatus acusticus externus, C Bulla tympanica .

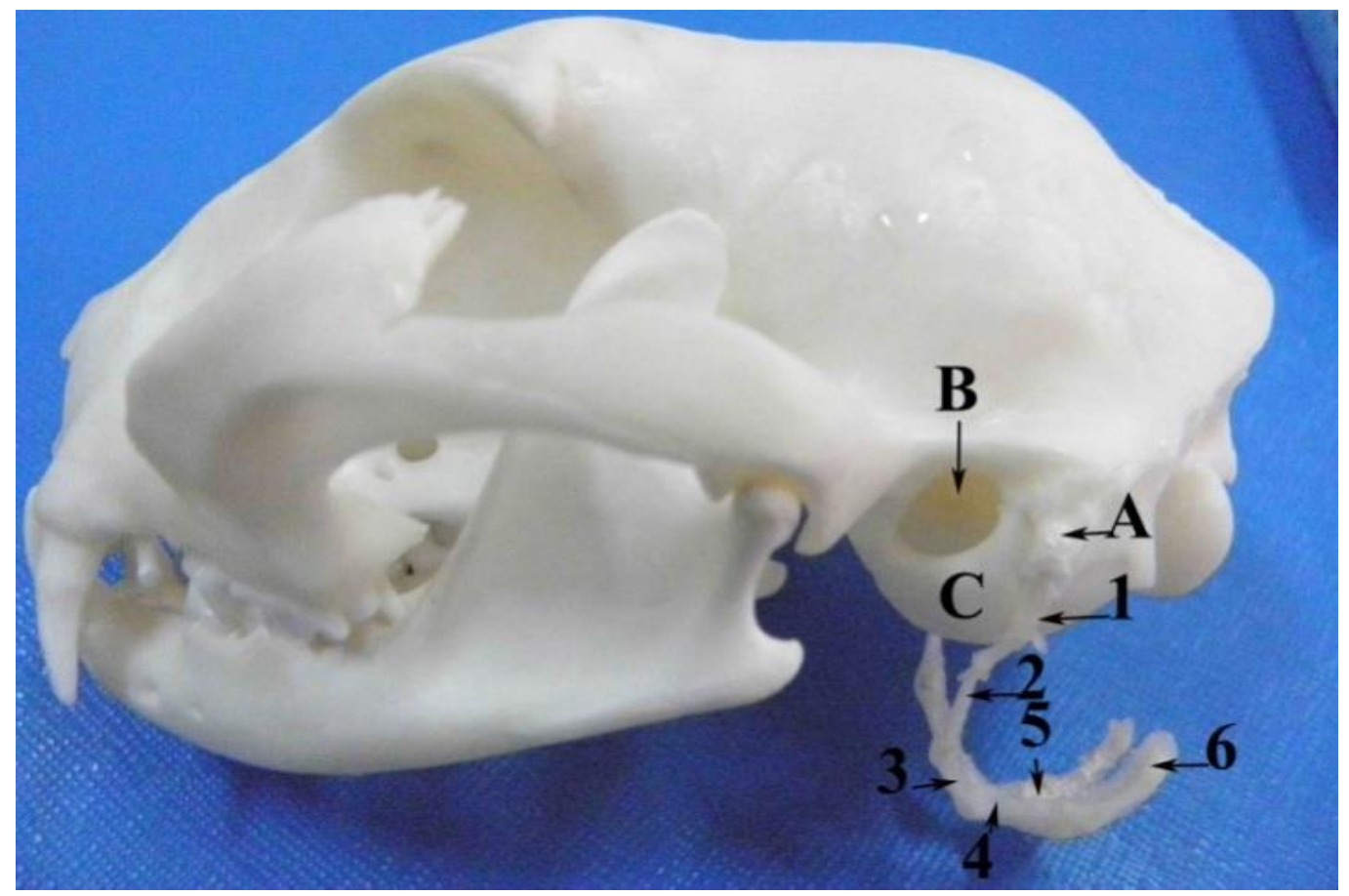

Fig (1): Left lateral view of the hyoid apparatus of the domestic cat showing its articulation with the skull base. 

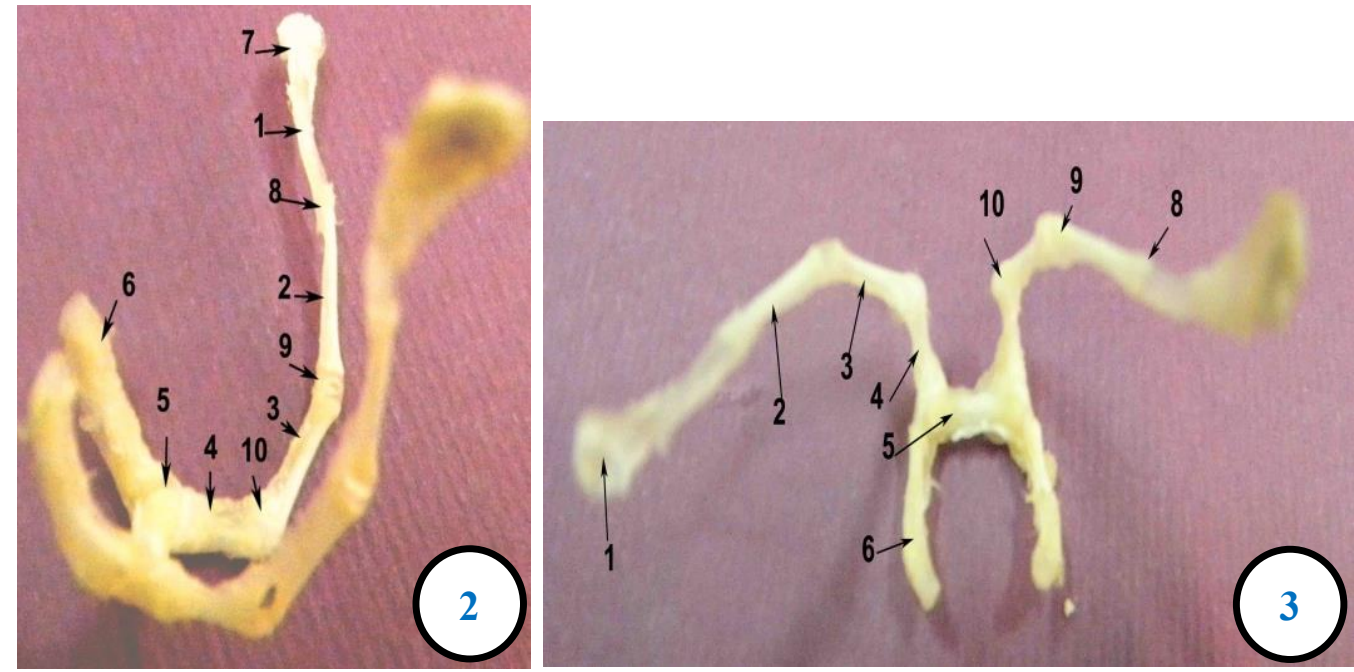

Fig (2): Right lateral view of the hyoid apparatus of the domestic cat.

Fig (3): Dorsal view of the hyoid apparatus of the domestic cat.
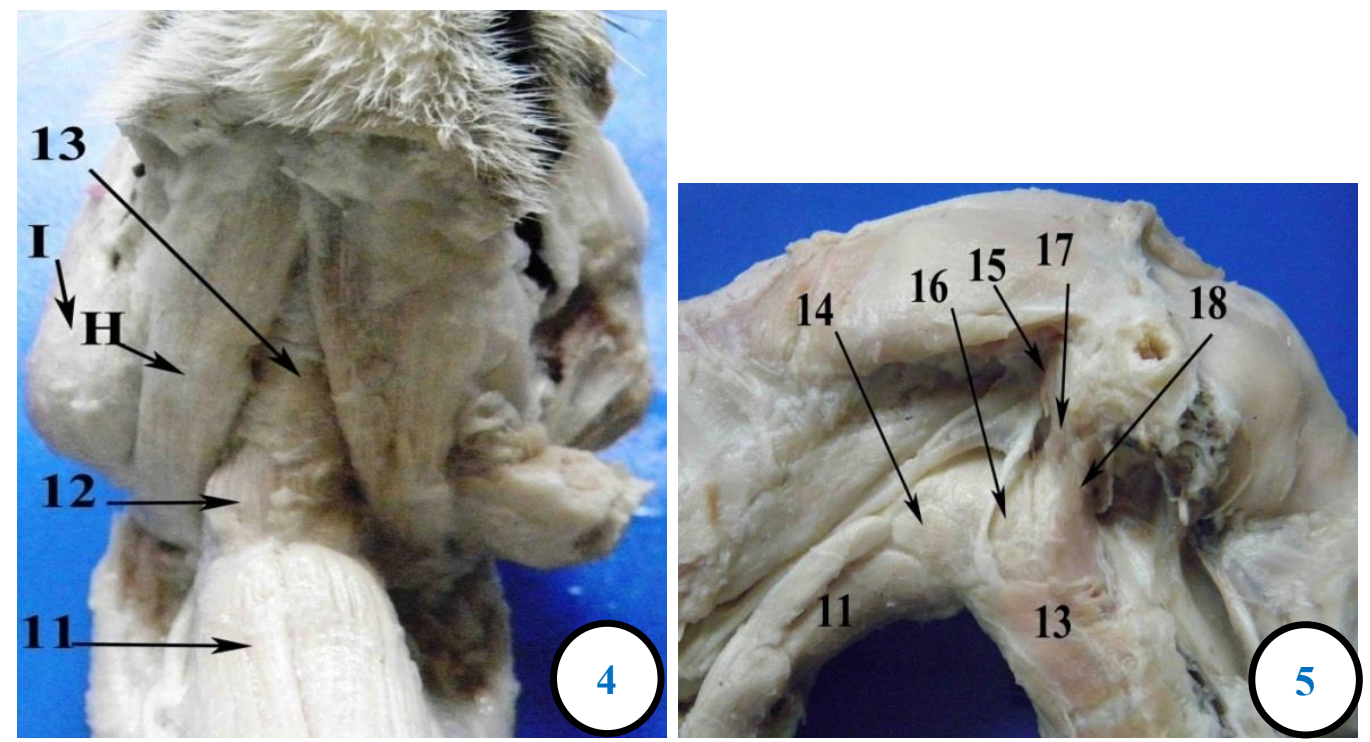

Fig (4): Ventral view of the head and neck of the domestic cat.

Fig (5): Right view of the deep dissection of the head of the domestic cat. 

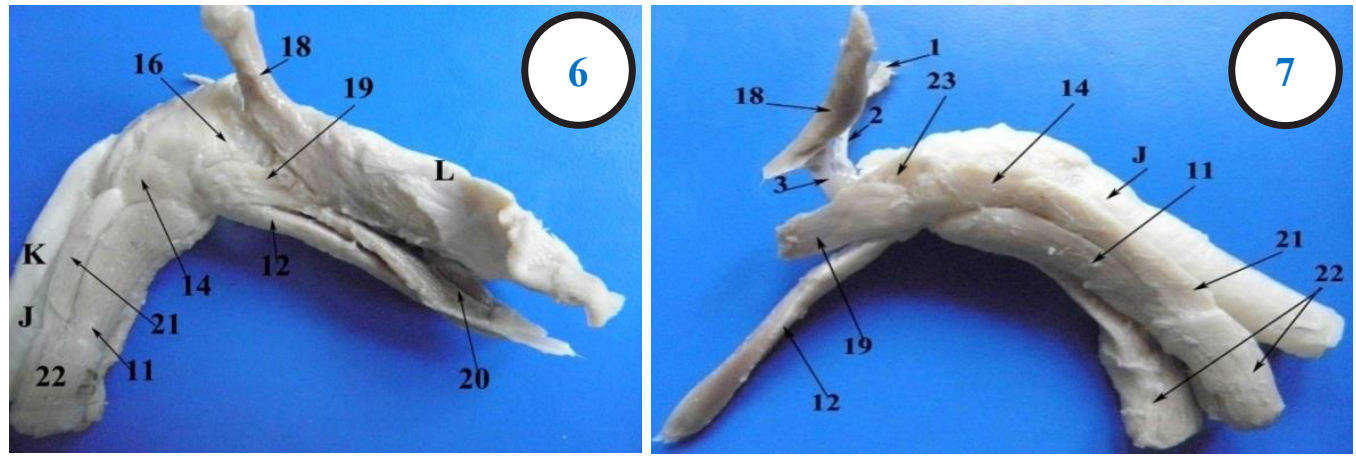

Fig (6): Right view of the hyoid muscles of the domestic cat.

Fig (7): Left view of the hyoid muscles of the domestic cat after removal of the tongue and pharynx.
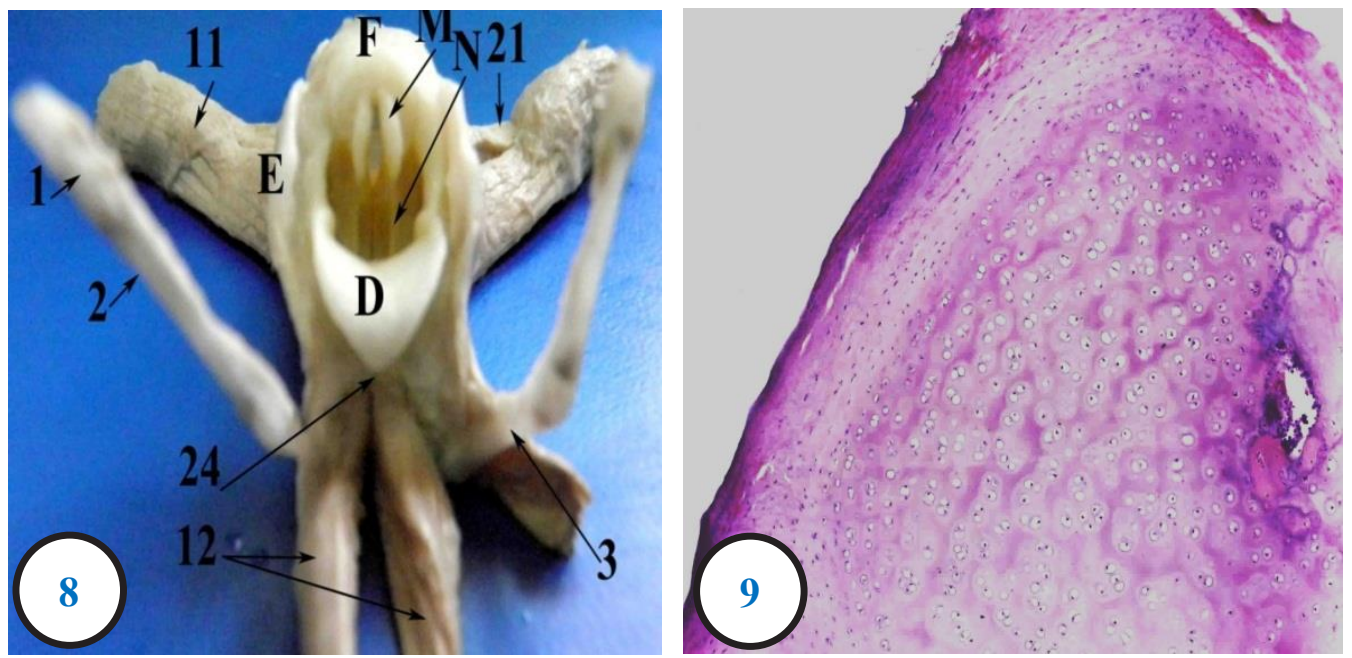

Fig (8): Rostral view of the hyoid apparatus and larynxof the domestic cat after removal of the tongue and pharynx.

Fig (9): Photomicrograph of the Tympanohyoideum, the hyaline cartilage.

H\&E stain, X10 

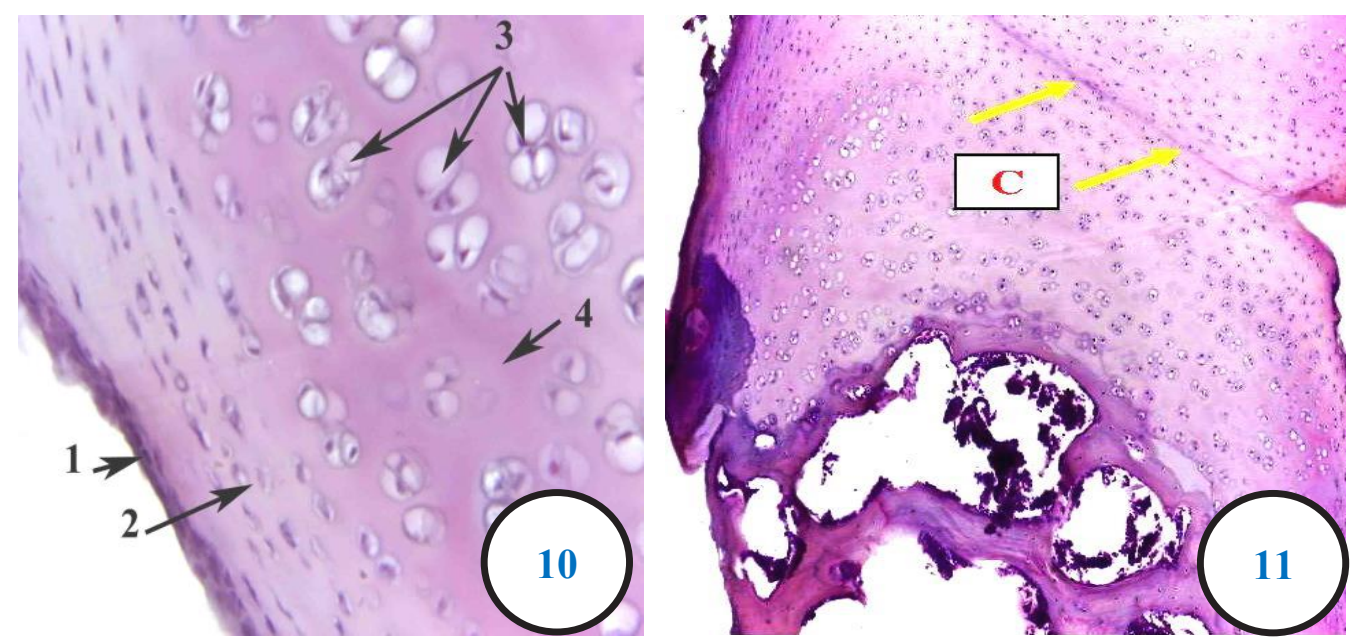

Fig (10): Photomicrograph of the tympanohyoideum showing the hyaline cartilage. Notice the perichondrium (1) chondroblasts (2) chondrocytes (3) and the matrix (4). H\&E stain, X40

Fig (11): Photomicrograph at the junction between the Tympanohyoideum and Stylohyoideum. Notice the hyaline cartilage synchondrosis (C) (arrow).

H\&E stain, X10

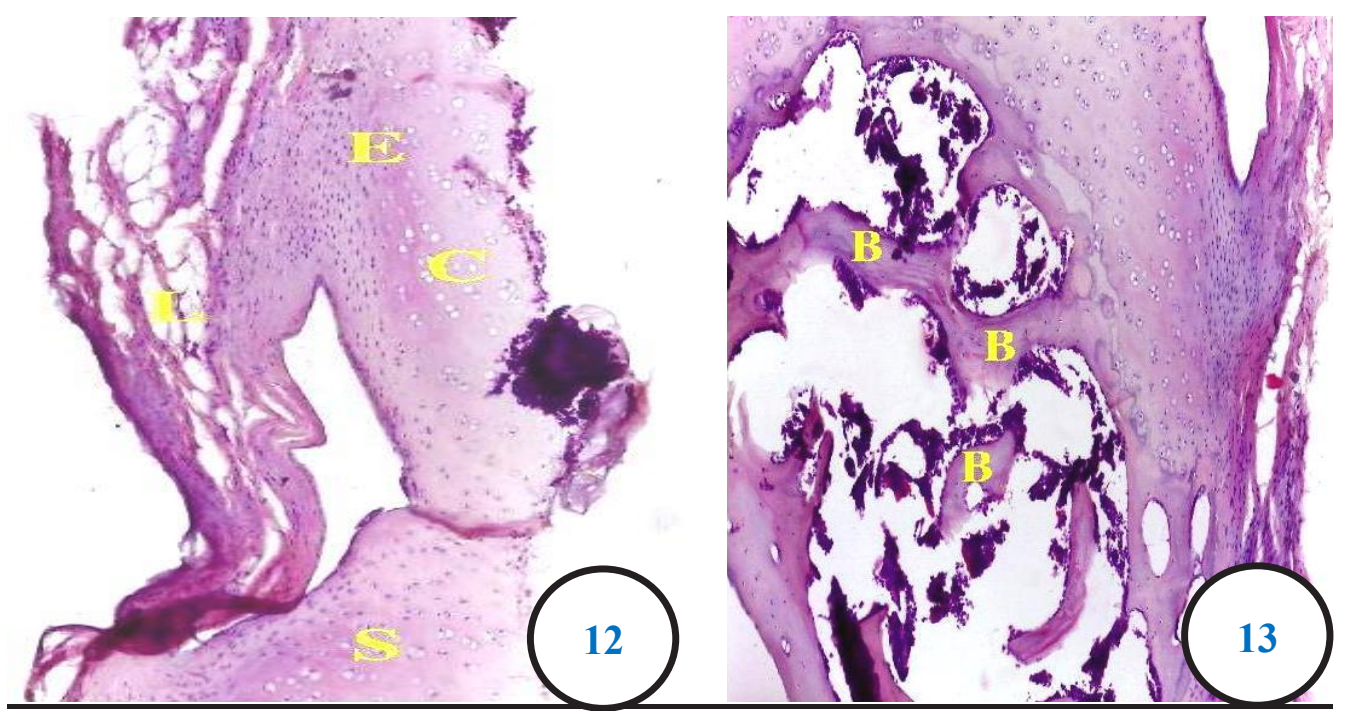

Fig (12): Photomicrograph of the stylohyoideum, showing that the spongy bones (B) present in the center surrounded by the hyaline cartilage.

H\&E stain, X10

Fig (13): Photomicrograph of the Epihyoideum which formed of hyaline cartilage (C) and fibrous part (L). Notice the synchondrosis ( white arrow) between Epihyoideum (E) and Cerartohyoideum (S). H\&E stain, X10 


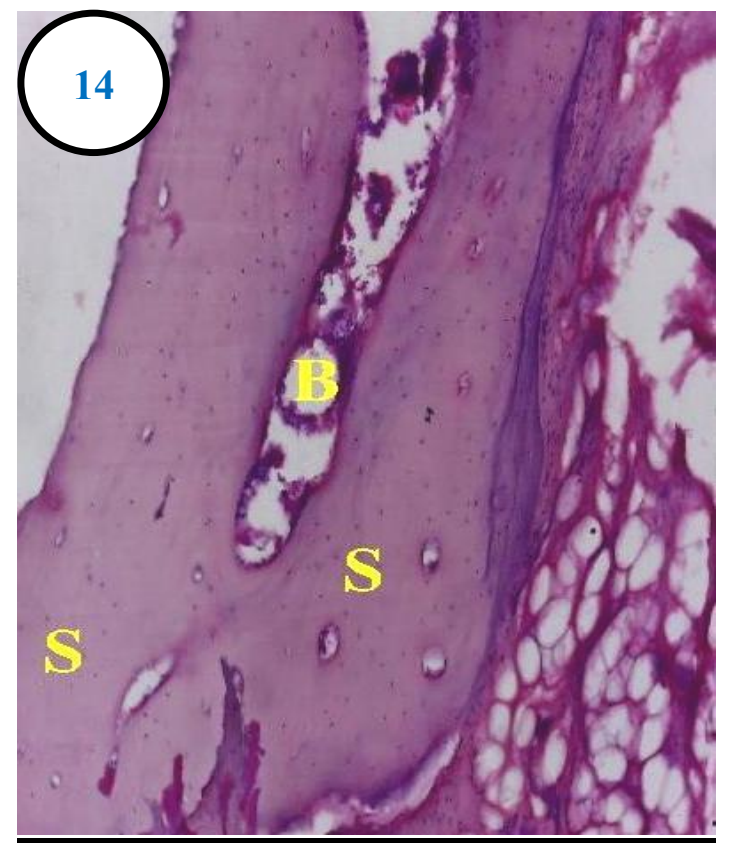

Fig (14): Photomicrograph of the Basihyoideum showing the spongy bone (S) and marrow cavity (B).

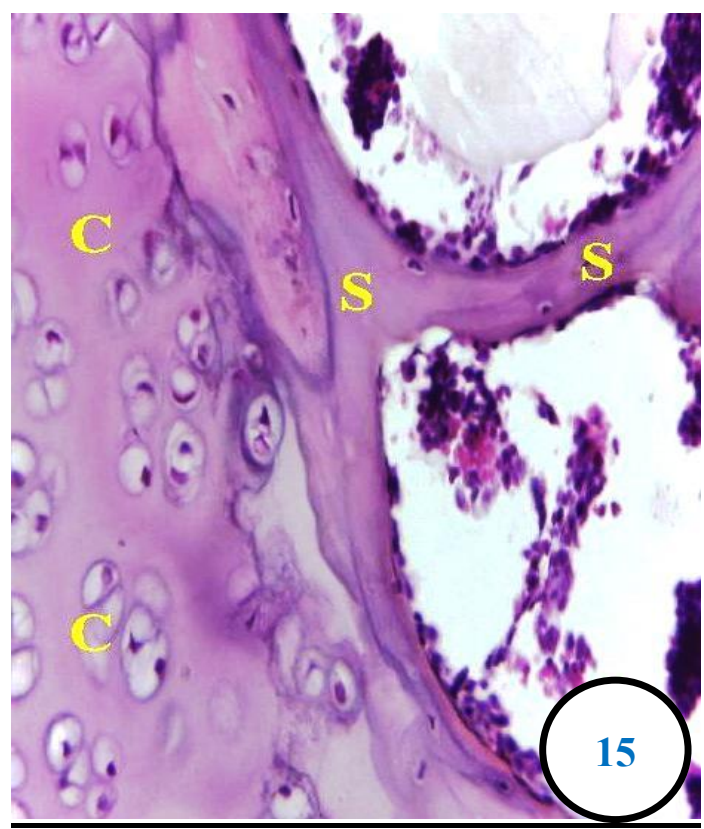

Fig (15): Photomicrograph of the Thyrohyoideum, showing the hyaline cartilage(C) and spongy bones (S). H\&E stain, X40 